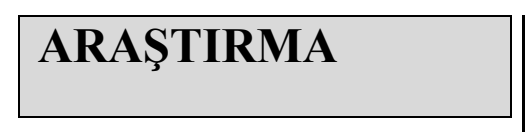

Erkan Gürkaş ${ }^{1}$ Mehmet Kiraz ${ }^{1}$ Mithat Temizer ${ }^{2}$

${ }^{1}$ Gaziantep İstasyon Aile Sağlığı Merkezi, Gaziantep ${ }^{2}$ Gaziantep Üniversitesi Halk Sağllğı AD, Gaziantep

İletişim Adresi:

Uz. Dr. Erkan Gürkaș

Aile Hekimliği Uzmanı, Gaziantep Istasyon Aile Sağglı̆̆ Merkezi, Gaziantep

Tel: 03124175190

E-mail:egurkas@yahoo.com

Konuralp Tıp Dergisi

e-ISSN1309-3878

konuralptipdergi@duzce.edu.tr konuralpgeneltip@gmail.com $\underline{\text { www.konuralptipdergi.duzce.edu.tr }}$

\section{Gaziantep İli İstasyon Aile Sağlığı Merkezi'ne Başvuran Erişkinlerde Obezite Sıklığı}

\begin{abstract}
ÖZET
Obezite tüm dünyada ve ülkemizde giderek prevalansı artan önemli bir halk sağlı̆̆ı sorunudur.

Bu çalışmanın amacı; Gaziantep İli İstasyon Aile Sağlı̆̆ Merkezi’nde Aralık 2011 ile Haziran 2012 tarihleri arasında 20 yaş ve üzeri erişkinlerde obezite prevalansını belirlemektir. Çalışmaya 2568 kişi dahil edildi. Bunların \%58'i (1494) kadın, \%42'si (1074) erkekti. Kișilerin boy ve vücut ağırlığı ölçümleri yapılarak vücut kitle indeksi (VKI') $30 \mathrm{~kg} / \mathrm{m}^{2}$ ve üzeri olanlar obez olarak kabul edildi. Tüm popülasyonda obezite sıklığ $\% 27.5$ olarak bulundu. Erkeklerde obezite prevalans $1 \% 24$, kadınlarda ise \%29.7 idi.

Sonuç olarak; obezite ülkemizde sıklığı giderek artan, ciddi sosyal, psikolojik ve ekonomik sorunlara yol açan önemli bir hastalık olarak kabul edilmelidir. Obezitenin önlenmesi amacıyla etkili sağlık politikaları uygulanmalıdır.

Anahtar Kelimeler: Obezite, Prevalans, Erişkin.
\end{abstract}

\section{The Prevalence of Obesity in Adults who Applied to Gaziantep İstasyon Family Health Center}

\footnotetext{
ABSTRACT

Obesity is an important public health problem that has an increasing prevalence in our country and also in the world.

The aim of this study is to determine the prevalence of obesity in adults aged 20 and older who applied to Gaziantep İstasyon Family Health Center between December 2011 and June 2012.The population of the study was 2568 adults.58\% (1494) of them were female and the rest $42 \%$ (1074) were male. The measurement of height and weight was done. Body mass index (BMI) was calculated for each individual. People whose body mass indexes were $30 \mathrm{~kg} / \mathrm{m}^{2}$ and higher were accepted as obese. The prevalence of obesity in overall population was $27.5 \%$. This prevalence was $24 \%$ in adult men and $29.7 \%$ in adult women.

As a result; obesity, which has an increasing prevalence in our country and causes serious social, psychological and economical problems should be accepted as an important disease. For prevention of obesity, efficient health policies should be applied.

Key Words: Obesity, Prevalence, Adult.
} 


\section{GiRiş}

Obezite, Dünya Sağlık Örgütü (DSÖ) tarafindan sağlığı bozacak ölçüde vücutta anormal veya aşırı yağ birikmesi olarak tanımlanmaktadır(1). DSÖ verilerine göre, obezite 300 milyonun üzerinde insanı etkilemektedir. Yaklaşık bir milyar kişi ise, aşırı kilolu gruptadır (2). Giderek artan sıklığı ile obezite, tıbbi harcamalar ve iş gücü kaybı nedeniyle yıllık 100 milyar dolardan fazla bir kayba sebebiyet vermektedir (3).

Obezite daha önceleri sağlıklı olmanın bir göstergesi olarak algılanmakta iken; günümüzde hem kendisi bir hastalık, hem de ciddi sosyal, psikolojik ve ekonomik sorunlara yol açan, yaşam boyu sürecek çeşitli hastalıklara zemin hazırlayan bir durum olarak kabul edilmektedir $(4,5)$.

Obezitenin kadınlarda endometriyum, ovaryum ve meme kanserleri, amenore, preeklampsi; erkeklerde prostat kanseri, her iki cinste bazı gastrointestinal sistem kanserleri, kolelitiyazis, infertilite, dejeneratif artrit, hipertansiyon ve tip 2 diyabet gibi hastalıklarla yakın ilişkili olduğuna dair çalışmalar vardır $(6,7)$. Obez kişilerde bu tip hastalıkların insidansının artması yanında fatalite hızının da arttığı bildirilmektedir (8). Kara ve ark.'larının üreme çağındaki kadınlar arasında yaptığı bir çalışmada, obez olmayan kadınlarda hipertansiyon ko-morbiditesi \%2.9 iken, obez kadınlarda bu değer \%35.9'a çıkmaktadır(9).

DSÖ’nün 1983-1986 yılları arasında yaptığı uluslararası bir çalışmanın verilerine göre; Avrupa'da obezite prevalans1 erkeklerde \%64.2, kadınlarda \%56.3'tür (10). Obezite prevalans1 ülkemizde de giderek artmaktadır. 24788 kişinin katıldığı TURDEP 1 çalışmasının sonuçlarına göre; Türkiye'de kadınlarda \%30,erkeklerde \%13, genelde ise $\% 22.3$ olmak üzere obezite prevalans1 tesbit edilmiştir (11).

TURDEP 2 çalışmasında ise; Türkiye'de 12 y1l içerisinde obezite artışı kadınlarda \%34, erkeklerde ise \%107 olarak gerçekleşmiştir (12). Obezitenin ölçümünde birçok yöntem kullanılmaktadır. En çok kullanılan obezite belirleme yöntemi, 'Vücut Kitle İndeksi (VKİ)' dir. VKİ; ağırlık/boy2 formülü ile hesaplanmaktadır $(10,13)$. DSÖ'nün VKİ sınıflaması Tablo 1'de gösterilmiştir. Bu çalışmada, Aralık 2011-Haziran 2012 tarihleri arasında Gaziantep İli İstasyon Aile Sağlı̆̆ Merkezi'ne başvuran 20 yaş ve üzeri erişkinlerde obezite sıklı̆ğının araştııılması hedeflenmiştir.

\section{GEREC VE YÖNTEM}

Araştırmaya Aralık 2011-Haziran 2012 tarihleri arasında Gaziantep İli İstasyon Aile Sağlığ Merkezi'ne başvuran 2568 adet 20 yaş ve üstü kişi dahil edilmiştir. Kişilerin boy ve vücut ağırlığ ölçümleri yapılıp, vücut ağırlı̆̆ $(\mathrm{kg}) /$ boy2 (m2) formülü kullanılarak VKİ'leri hesaplanmıştır.

VKİ genel popülasyonda, erkeklerde ve kadınlarda yaşa göre sinıflandırılmıştır. $\quad \mathrm{VK} \dot{\mathbf{I}}<18.5 \quad \mathrm{~kg} / \mathrm{m} 2$ olanlar zayıf, 18.5 ile $24.9 \mathrm{~kg} / \mathrm{m} 2$ arasında olanlar normal kilolu, 25 ile $29.9 \mathrm{~kg} / \mathrm{m} 2$ arasında olanlar kilolu,30 ile $39.9 \mathrm{~kg} / \mathrm{m} 2$ olanlar obez ve $>=40$ $\mathrm{kg} / \mathrm{m} 2$ olanlar aşırı obez olarak kabul edilmiştir. Genel popülasyon, kadınlar ve erkekler ayrı ayrı, 20-29, 30-39, 40-49, 50-59, 60-69, 70 yaş ve üzeri olmak üzere sınıflandırılmıştır.

Veriler, Microsoft Office Excel 2007 programina girilerek, oranlar hesaplanmış ve tanımlayıcı tablolar oluşturulmuştur. İstatistiksel analizler Epi info 7 programı kullanılarak yapılmıştır. Kikare testi yapılıp, Yates düzeltmesi uygulanmıștır.

Tablo 1.DSÖ’ nün VKİ sınıflaması

\begin{tabular}{|l|l|}
\hline VKİ(kg/m2) & TANIM \\
\hline$<18.5$ & Düşük kilolu \\
\hline $18.5-24.9$ & Normal \\
\hline $25-29.9$ & Evre 1 aşırı kilolu \\
\hline $30-39.9$ & Evre 2 aşırı kilolu \\
\hline$>=40$ & Evre 3 aşırı kilolu \\
\hline
\end{tabular}

\section{BULGULAR}

Araştırmaya dahil edilen toplam kiși sayısı 2568 idi. Bunların \%58'i (1494 kişi) kadın, \%42'si (1074 kişi) erkekti. Genel popülasyona baktığımızda, VKİ $30 \mathrm{~kg} 7 \mathrm{~m} 2$ ve üzerinde olanlar çoğunlukla 30 ile 59 yaş arasında idi.30 yaşın altında ve 60 yaşın üzerinde obezite sıklığı azalmaktaydı. Obezite sıklığının en fazla olduğu yaş grubu 40-49 yaş grubuydu. Genel popülasyonda obezite prevalans1 $\% 27.5$ 'ti (Tablo 2).

Kadın popülasyonuna baktığımızda; VKİ $30 \mathrm{~kg} / \mathrm{m} 2$ ve üzerinde olanlar çoğunlukla 40 ile 59 yaş arasında idi. Bu yaşların altında ve üzerinde obezite sıklığı giderek azalmaktaydı. Obezite sıklığının en fazla olduğu yaş grubu 40-49 yaş grubuydu. Kadınlarda obezite prevalans1 \%29.7 idi (Tablo 3). Erkek popülasyonuna baktığımızda; VKİ $30 \mathrm{~kg} / \mathrm{m} 2$ ve üzerinde olanlar çoğunlukla 30-49 yaş aralığındaydı. $\mathrm{Bu}$ yaşların altında ve üzerinde obezite sıklığı gittikçe azalmaktaydı. Obezite sıklığının en fazla olduğu yaş grubu 40-49 yaş grubuydu. Erkeklerde obezite prevalans1 \%24 idi (Tablo 4).

Kadınların 367'si (\%24.56) obez (BMI >=30), erkeklerin ise 258'i (\%24.02) obezdi. Kadınlar ve erkekler arasında, obezite görülme sıklığı açısından istatistiksel olarak anlamlı bir fark bulunamadı (Tablo5).

Kadınların 40' ' (\%2.68) zayıf (BMI $<18)$, erkeklerin ise 16 's1 (\%1.49) zayıftı. Her iki grup arasında zayıflık sıklığı açısından istatistiksel olarak anlamlı bir fark bulunamadı ( $>0.05$ ). Tüm populasyonda, 40 yaş altında 221 kişi $(\% 15.65)$ obezdi (BMI>=30). 40 yaş ve üzerinde ise bu rakam 483 'tü (\%41.78). Her iki grup arasında, obezite görülme sıklığının istatistiksel olarak anlamlı düzeyde farklı olduğu saptandı (Tablo 6).Kadın populasyonunda, 40 yaş altında 127 kişi (\%15.05),40 yaş ve üzerinde ise 318 kişi $(\% 48,92)$ obezdi. Her iki grup arasında obezite görülme sıklığının istatistiksel olarak 
anlamlı düzeyde farklı olduğu saptandı (Tablo 7). Erkek populasyonunda, 40 yaş altında 94 kişi (\%16.55), 40 yaş ve üzerinde ise 164 kişi (\%32.4) obezdi. Her iki grup arasında da obezite görülme sıklığının istatistiksel olarak anlamlı olduğu saptandı (Tablo 8). Kadın ve erkek populasyonundaki X2 değerlerine bakacak olursak; kadın populasyonundaki farkın (X2=199.8705), erkek populasyonundaki farktan $(\mathrm{X} 2=36.0250)$ daha belirgin olduğu göze çarpmaktadır (Tablo 7 ve 8).

Tablo 2. Genel popülasyonda yaşa göre obezite sıklığı

\begin{tabular}{|l|c|c|c|c|c|}
\hline YAŞ/VKI & $<\mathbf{I}$ | & $\mathbf{1 8 . 5 - 2 4 . 9}$ & $\mathbf{2 5 - 2 9 . 9}$ & $\mathbf{3 0 - 3 9 . 9}$ & $>=\mathbf{4 0}$ \\
\hline $20-29$ & $43(\% 1.7)$ & $402(\% 15.8)$ & $155(\% 6)$ & $64(\% 2.5)$ & $2(\% 0.07)$ \\
\hline $30-39$ & $9(\% 0.3)$ & $276(\% 10.8)$ & $306(\% 11.9)$ & $150(\% 5.9)$ & $5(\% 0.2)$ \\
\hline $40-49$ & $3(\% 0.1)$ & $121(\% 4.7)$ & $251(\% 9.8)$ & $167(\% 6.6)$ & $19(\% 0.7)$ \\
\hline $50-59$ & $1(\% 0.03)$ & $50(\% 1.9)$ & $113(\% 4.4)$ & $130(\% 5)$ & $17(\% 0.6)$ \\
\hline $60-69$ & $0(\% 0)$ & $22(\% 0.8)$ & $58(\% 2.3)$ & $86(\% 3.4)$ & $16(\% 0.6)$ \\
\hline$>=70$ & $0(\% 0)$ & $22(\% 0.8)$ & $33(\% 1.3)$ & $42(\% 1.6)$ & $6(\% 0.2)$ \\
\hline
\end{tabular}

$\mathrm{X} 2=570, \mathrm{p}<0.0001$

Tablo 3. Kadınlarda yaşa göre obezite sıklığı

\begin{tabular}{|l|c|c|c|c|c|}
\hline YAŞ/VKI & $<\mathbf{1 8 . 5}$ & $\mathbf{1 8 . 5 - 2 4 . 9}$ & $\mathbf{2 5 - 2 9 . 9}$ & $\mathbf{3 0 - 3 9 . 9}$ & $>=40$ \\
\hline $20-29$ & $29(\% 1.9)$ & $261(\% 17.5)$ & $80(\% 5.3)$ & $37(\% 2.5)$ & $1(\% 0.05)$ \\
\hline $30-39$ & $7(\% 0.5)$ & $178(\% 11.9)$ & $162(\% 10.9)$ & $86(\% 5.7)$ & $3(\% 0.2)$ \\
\hline $40-49$ & $3(\% 0.2)$ & $66(\% 4.4)$ & $138(\% 9.3)$ & $91(\% 6.1)$ & $15(\% 1)$ \\
\hline $50-59$ & $1(\% 0.05)$ & $25(\% 1.7)$ & $40(\% 2.7)$ & $90(\% 6)$ & $13(\% 0.9)$ \\
\hline $60-69$ & $0(\% 0)$ & $6(\% 0.4)$ & $30(\% 2)$ & $61(\% 4.1)$ & $13(\% 0.9)$ \\
\hline$>=70$ & $0(\% 0)$ & $8(\% 0.5)$ & $15(\% 1)$ & $31(\% 2)$ & $4(\% 0.3)$ \\
\hline
\end{tabular}

$\mathrm{X} 2=399, \mathrm{p}<0.0001$

Tablo 4. Erkeklerde yaşa göre obezite sıklığı

\begin{tabular}{|l|c|c|c|c|c|}
\hline YAŞ/VKI & $<\mathbf{1 8 . 5}$ & $\mathbf{1 8 . 5 - 2 4 . 9}$ & $\mathbf{2 5 - 2 9 . 9}$ & $\mathbf{3 0 - 3 9 . 9}$ & $>=40$ \\
\hline $20-29$ & $14(\% 1.3)$ & $141(\% 13.1)$ & $75(\% 7)$ & $27(\% 2.5)$ & $1(\% 0.1)$ \\
\hline $30-39$ & $2(\% 0.2)$ & $98(\% 9.1)$ & $144(\% 13.5)$ & $64(\% 6)$ & $2(\% 0.2)$ \\
\hline $40-49$ & $0(\% 0)$ & $55(\% 5.1)$ & $113(\% 10.6)$ & $76(\% 7)$ & $4(\% 0.4)$ \\
\hline $50-59$ & $0(\% 0)$ & $25(\% 2.3)$ & $73(\% 6.8)$ & $40(\% 3.7)$ & $4(\% 0.4)$ \\
\hline $60-69$ & $0(\% 0)$ & $16(\% 1.5)$ & $28(\% 2.6)$ & $25(\% 2.3)$ & $2(\% 0.2)$ \\
\hline$>=70$ & $0(\% 0)$ & $14(\% 1.3)$ & $18(\% 1.6)$ & $11(\% 1)$ & $2(\% 0.2)$ \\
\hline
\end{tabular}

$\mathrm{X} 2=151, \mathrm{p}<0.0001$

Tablo 5. Kadınlarda ve erkeklerde obezite (BMI>=30) görülme sıklığının karşılaştırılması

\begin{tabular}{|l|c|c|c|}
\hline & OBEZ & OBEZ OLMAYAN & TOPLAM \\
\hline Kadın & $367(\% 24.56)$ & $1127(\% 75.44)$ & $1494(\% 100)$ \\
\hline Erkek & $258(\% 24.02)$ & $816(\% 75.98)$ & $1074(\% 100)$ \\
\hline TOPLAM & 625 & 1943 & 2568 \\
\hline
\end{tabular}

$\mathrm{X} 2=0.0726$ Yates düzeltmesi yapılmıştır. İki uçlu $\mathrm{p}=0.787$

Tablo 6. Tüm populasyonda 40 yaş altı ve üstünde obezite (BMI>=30) görülme sıklığının karşılaştırılması

\begin{tabular}{|l|c|c|c|}
\hline & OBEZ & OBEZ OLMAYAN & TOPLAM \\
\hline 40 Yaş Alt1 & $221(\% 15.65)$ & $1191(\% 84.33)$ & $1412(\% 100)$ \\
\hline 40 Yaş Ve Üstü & $483(\% 41.78)$ & $673(\% 58.22)$ & $1156(\% 100)$ \\
\hline TOPLAM & 704 & 1864 & 2568 \\
\hline
\end{tabular}

$\mathrm{X} 2=216.7924$ Yates düzeltmesi yapılmıștır. İki uçlu $\mathrm{p}<0.0001$

Tablo 7. Kadınlarda 40 yaș altı ve üstünde obezite (BMI>=30) görülme sıklığının karșılaștırılması

\begin{tabular}{|l|c|c|c|}
\hline & OBEZ & OBEZ OLMAYAN & TOPLAM \\
\hline 40 Yaş Alt1 & $127(\% 15.05)$ & $717(\% 84.95)$ & $844(\% 100)$ \\
\hline 40 Yaş Ve Üstü & $318(\% 48.92)$ & $332(\% 51.08)$ & $650(\% 100)$ \\
\hline TOPLAM & 445 & 1049 & 1494 \\
\hline
\end{tabular}

$\mathrm{X} 2=199.8705$ Yates düzeltmesi yapılmıştır. İki uçlu $\mathrm{p}<0.0001$

Tablo 8. Erkeklerde 40 yaş altı ve üstünde obezite (BMI>=30) görülme sıklığının karşılaştırılması

\begin{tabular}{|l|c|c|c|}
\hline & OBEZ & OBEZ OLMAYAN & TOPLAM \\
\hline 40 Yaş Alt1 & $94(\% 16.55)$ & $474(\% 83.45)$ & $568(\% 100)$ \\
\hline T0 Yaş Ve Üstü & $164(\% 32.41)$ & $342(\% 67.59)$ & $506(\% 100)$ \\
\hline XOMLA & 258 & 816 & 1074 \\
\hline
\end{tabular}

$\mathrm{X} 2=36.0250$ Yates düzeltmesi yapılmıştır. İki uçlu $\mathrm{p}<0.0001$ 


\section{TARTIŞMA}

Gaziantep İli İstasyon Aile Sağlığı Merkezi'nde 20 yaş ve üzeri 2568 kişide obezite prevalansı $\% 27.5$ 'ti. Ülkemizde yapılan çalışmalarda obezite s1klığı \%22, \%25.2, \%35.5 ve \%28 olarak bulunmuştur (11,14-16). Akman ve ark'larının İstanbul Haseki Hastanesi'nde yaptıkları çalışmada obezite sıklığı \%31.6 olarak bulunmuştur (17). 24788 kişinin katıldığ 1 TURDEP 1 çalışmasının sonuçlarına göre, obezite prevalans1 \%22.3'tür (11). Çalışmamızda bulduğumuz prevalans değeri Türkiye'de yapılan diğer çalışmaların değerleriyle uyumluluk göstermekteydi. Akman ve ark.'larının İstanbul'da yaptıkları çalışmada obezite sıklığının 40'lı yaşlardan itibaren artış gösterdiği ve 60'l1 yaşlarla birlikte göreceli olarak azaldığı saptanmıştır (17). Bizim çalışmamızda da obezite sıklığı 30 yaşın altında ve 60 yaşın üzerinde azalmaktayd1.

TURDEP 1 çalışmasının sonuçlarına göre; Türkiye'de kadınlarda obezite prevalansı \%30 olarak saptanmıştır (11). Bizim çalışmamızda da kadınlarda obezite prevalansı \%29.7 idi.
Bulduğumuz değer TURDEP 1 çalışmasıyla uyumluluk göstermekteydi.

TURDEP 1 çalışmasına göre, Türkiye'de erkeklerde obezite prevalansı \%13 olarak saptanmıştır (11). Ancak TURDEP 2 çalışmasında Türkiye'de 12 yıl içinde obezite artışı erkeklerde \%107 gerçekleşmiştir (12). Bizim çalışmamızda erkeklerde obezite prevalansı \%24 olarak saptanmıştır. Bu değer TURDEP 1 çalışmasındaki sonuca göre yüksektir. Ancak TURDEP 2 çalışmasında belirtilen \%107'lik prevalans artış1 göz önünde bulundurulduğunda, bu artıştan dolayı bizim çalışmamızın sonucunun yüksek çıkmış olabileceği düşünülmektedir.

Sonuç olarak, ülkemizde obezite sıklığ 1 giderek artan, ciddi sosyal, psikolojik ve ekonomik sorunlara yol açan önemli bir hastalık olarak kabul edilebilir. Ülke genelinde bu konuyla ilgili önleyici sağlık politikaları oluşturulmalı ve bu politikalar öncelikle birinci basamak sağlık kuruluşları olmak üzere tüm sağlık kuruluşlarında titizlikle uygulanmalidir.

\section{KAYNAKLAR}

1. World Health Organisation. Obesity and overweight fact.Report on a WHO Consultation on Obesity, Geneva: WHO, sheet no: 311. http:/who.int/mediacentre/factsheets/fs3117en/print.html.

2. World Health Organisation. Global strategy on diet, physical activity and health. WHO, 2008.

3. Sammel K, Johannes A. Romijn. Obesity. Williams Textbook of Endocrinology, 11th Edition. 2008:156387.

4. Y1lmaz C. Obezite. İstanbul: Nobel Tip Kitabevi, 1995; 1-17.

5. Baysal A. Şişmanlık. Beslenme 7. Baskı. Ankara: Hatipoğlu Yayınevi, 1997; 463-9.

6. Weitkamp E. Obesity, endocrine abnormalities and cancer. Berkshire: Colwood House Medical Publications, 1996;7-9.

7. Yurttagül M. Hafif şişman ve şişman kadınların beslenme alışkanlıkları ve zayıflamaya ilişkin tutum ve davranışları.Beslenme ve Diyet Dergisi 1995; 24(1):59-73.

8. Manson JE, Stampfer MJ, Hennekens CH, et al. Body weight and longevity. JAMA 1987; 257(3):353-358.

9. Kara İH, Baltacı D, Sayın S, et al. Üreme çağındaki obez kadınlarda hematolojik ve biyokimyasal parametrelerin incelenmesi. Konuralp T1p Dergisi 2012;4(1):1-7.

10. Seidell JC. Epidemiology: Definition and classification of obesity. Editors: Kopelman P, Stock MJ. Clinical Obesity, Oxford: Blackwell Science Ltd. 1998;1-17.

11. Satman İ, Şengül AM, Uygur S, et al. The TURDEP Group. Population based study of diabetes and risk characteristic in Turkey: Results of the Turkish diabetes epidemiology study (TURDEP). Diabetes Care 2002; 25(9):1551-6.

12. Satman İ, Alagöl F, Ömer B, et al. Türkiye diyabet, hipertansiyon, obezite ve endokrinolojik hastalıklar prevalans çalışması 2 (TURDEP 2). www.turkendocrin.

13. Ergün A. Obezite: Besin alımı ve vücut ağırlığının kontrolünde leptin. T Klin Tıp Bilimleri 1998;18 (1):2205.

14. Hatemi H, Turan N, Arık N, Yumuk V. Türkiye obezite ve hipertansiyon taraması sonuçları (TOHTA). Endokrinolojide Yönelişler Dergisi 2002;11(Ek 1):1-16.

15. Erden S. Poliklinik hastalarında obezite sıklığı ve klinik özellikleri. İ.Ü. İstanbul Tıp Fakültesi Mecmuası 2001;64(4):249-54.

16. Aladağ N, Ciğerli Ö, Topsever P, Filiz TM, Topallı R, Görpelioğlu S. Değirmendere Aile Hekimliği Polikliniği'ne başvuran erişkin hastalarda obezite sıklığı ve eşlik eden hastalıklarla ilişkisi: Bir olgu kontrol çalışması. Türk Aile Hek Derg 2003;7(3):117-21.

17. Akman M,Şennur B,Kendir M. Genel dahiliye polikliniğine başvuran hastalarda obezite sıklı̆̆ ve ilişkili sağlık problemleri. Marmara Medical Journal 2004;17(3):113-20. 